\title{
Abstract 2 \\ RESPONSES FROM SINGLE UNITS IN THE DORSAL COCHLEAR NUCLEUS TO ELECTRICAL STIMULATION OF THE COCHLEA
}

\author{
O'Leary S.J., Tong Y.C., Clark G.M. \\ Dept of Otolaryngology, University of Melbourne, Parkville, 3052, Australia.
}

To help improve our understanding of how the brain responds to electrical stimulation of the auditory nerve we have examined the responses of dorsal cochlear nucleus (DCN) units to both acoustic stimulation and electrical stimulation of the cochlea. This work extended our previous studies which have compared the responses to electrical and acoustic stimulation in the auditory nerve (Javel et al, 1987, Ann. Otol. Rhinol. Laryngol. Suppl. 128, 96:26$30)$ and the ventral cochlear nucleus (Shepherd et al, 1988, NIH Contract NOI-NS.7. 2342, 5th Quarterly Progress Report). The auditory nerve was activated by bipolar electrical stimulation of the cochlea using an electrode array similar to that used in the University of Melbourne-Cochlear Pty Ltd Multiple Channel Cochlear Implant. The electrical stimulus was a $100 \mathrm{~ms}$ duration acoustic tones and wideband noise at high stimulus intensity. To establish that the DCN responses recorded from hearing animals were due primarily to activation of the auditory nerve by the electrical stimulus, and not electrophonic mechanisms, DCN responses to electrical stimulation were compared from hearing animals and animal deafened to neomycin irrigation of the scala tympani. The latencies from stimulus pulses to action potentials was similar in both hearing and deaf animals. The envelope of the poststimulus time histograms (PSTH's) in response to electrical stimulation exhibited "primarylike", "onset" or "negative response" and less frequently "pauser" or "buildup" patterns. The PSTH patterns to electrical stimulation were observed with a similar frequency in hearing and deafened animals. Since the responses to electrical stimulation were similar from both hearing and deaf cats, they were probably generated by the same mechanisms. Since electrophonic mechanisms were not active in the deafened animal, the responses to electrical stimulation in both hearing and deaf animals were due primarily to direct activation of the auditory nerve by the stimulus current. Thus there were reasonable grounds for using a hearing animal to contrast the responses of DCN units to acoustic and electrical stimulation of the auditory nerve. The PSTH and discharge rate responses to electrical stimulation and noise stimulation corresponded more frequently than the responses to electrical stimulation and CF tone stimulation. This result was consistent with the auditory nerve responses to noise and electrical stimuli being similar in a way which was important to neural processing within the DCN. The auditory nerve responses to these stimuli were similar in that both activated auditory nerve fibres over a broad cochlear region, but each response had a different temporal structure. This suggested that the DCN responded similarly to acoustic and electrical stimuli which activated broad cochlear regions. 


\section{University Library}

\section{- M M N E R VA A gateway to Melbourne's research publications}

Minerva Access is the Institutional Repository of The University of Melbourne

Author/s:

O'Leary, S. J.;Tong, Y. C.;Clark, Graeme M.

Title:

Responses from single units in the dorsal cochlear nucleus to electrical stimulation of the cochlea

Date:

1992

Citation:

O'Leary, S. J., Tong, Y. C., \& Clark, G. M. (1992). Responses from single units in the dorsal cochlear nucleus to electrical stimulation of the cochlea. In International Symposium Cochlear Implants - New Perspectives, Toulouse.

Persistent Link:

http://hdl.handle.net/11343/26878 